\title{
Neuropathy in female dental personnel exposed to high frequency vibrations
}

\author{
Ingrid Åkesson, Göran Lundborg, Vibeke Horstmann, Staffan Skerfving
}

\begin{abstract}
Objective-To evaluate early neuropathy in dental personnel exposed to high frequency vibrations.

Methods-30 dentists and 30 dental hygienists who used low and high speed hand pieces and ultrasonic scalers were studied, and 30 dental assistants and 30 medical nurses not exposed to vibration (all women). Vibrotactile sensibility, strength, motor performance, sensorineural symptoms and signs, and vascular symptoms in the hands, as well as mercury concentrations in biological samples and cervicobrachial symptoms, were studied.
\end{abstract}

Results-The two groups exposed to vibration had significant impairments of vibrotactile sensibility, strength, and motor performance, as well as more frequent sensorineural symptoms. In the dentists there were significant associations between the vibrotactile sensibility and strength, motor performance, superficial sensibility, and sensorineural symptoms. There were no associations between these findings and cervicobrachial symptoms, mercury concentrations, or smoking. There was no increase of vascular symptoms of the hands in the groups exposed to vibration.

Conclusion-Dental hygienists and dentists had a slight neuropathy, which may be associated with their exposure to high frequency vibrations, and which may be detrimental to their work performance. Thus, development of safer equipment is urgent.

(Occup Environ Med 1995;52:116-123)

Department of

Occupational and

Environmental

Medicine, University

Hospital, S-221 85

Lund, Sweden

I Åkesson

V Horstmann

S Skerfving

Division of Hand

Surgery, Department

of Orthopedic Surgery,

Lund University,

General Hospital, S-

21401 Malmö, Sweden

G Lundborg

Correspondence to:

Ingrid Akesson, Departmen of Occupational and Environmental Medicine University Hospital, S-22 85 Lund, Sweden.

Accepted 15 September 1994

Keywords: vibrations; dentists; sensory and motor function

The vibration in many hand held tools or work pieces may cause a complex of vascular, neurological, and musculoskeletal disturbances. ${ }^{1-3}$ The neural effects may occur independently of the circulatory disturbances. ${ }^{3}$ The pathophysiological mechanisms involved in the peripheral neural changes are not fully understood. ${ }^{13}$ Dental personnel are often exposed to vibrations, particularly high frequency hand vibrations of $6000-40000 \mathrm{~Hz}$, caused by high speed hand pieces and ultrasonic scalers. The exposure varies considerably among different categories of personnel.
Thus, dentists in particular use high speed hand pieces, whereas in dental hygienists the use of ultrasonic scalers is particularly frequent.

Circulatory disturbances have been suspected in dentists. ${ }^{4}$ Impaired vibrotactile perception has been found in dentists ${ }^{56}$ and in dental technicians ${ }^{7}$ (dental hygienists have not been studied). Further, carpal tunnel syndrom has been reported in dentists ${ }^{8}$ and dental hygienists. ${ }^{9}$

Vibration is not the only possible explanation of these neurological findings. Dental work involves repeated and monotonous movements of the hands that may cause carpal tunnel syndrome. ${ }^{10}$ Also, dental personnel have a high prevalence of disorders of the neck and shoulders, ${ }^{11}$ which may be associated with peripheral symptoms. There is also exposure to mercury vapour, ${ }^{12}$ which may cause disturbances of the peripheral nervous system. ${ }^{13}$

Peripheral vascular and sensorineural disorders of the fingers and hands might seriously affect the ability to fulfil the high precision demands of dentistry; especially dentists and dental hygienists need extremely good finger mobility and tactile sensitivity. Such work also requires good hand strength. Disturbances of these functions may make it impossible to continue working in these professions.

The aim of our study was to investigate, through a battery of tests, the occupational risk of development of neurological and functional disturbances of the hands among dental hygienists (not studied before) and dentists, who use hand held tools with high frequency vibrations. Associations between the different outcome variables were also analysed, as well as the possible associations with mercury exposure and musculoskeletal symptoms.

\section{Subjects and methods}

SUBJECTS

Dental personnel

The group studied consisted of dental hygienists and dental assistants, 30 in each group, who were all women. Also 30 women dentists (general practitioners) were studied. The dentists had a mean (range) age of 40 (28-57); duration of employment $13.6(1 \cdot 2-30)$ years: the dental assistants had an age of 37.3 (25-57) years; duration of employment $15 \cdot 1$ (2.7-39) years: the dental hygienists had an age of $41.5(28-52)$ years; duration of employment $7.5(2.8-17 \cdot 7)$ years. Also there was exposure to vibration during the educa- 
tion period, two years for the dental hygienists and five years for the dentists.

The dentists comprised all the female general practitioners in an earlier study of dental personnel in the public dental health service in the county of Blekinge. ${ }^{12}$ The dental assistants (also exposed to mercury vapour) were sampled by stratified matching (sex and age \pm 5 years) from the same population. The dental hygienists were the only six in Blekinge ${ }^{12}$ and 24 from the county of Malmöhus. The dental hygienists from Malmöhus were selected to match the total group by age to the dentists. All invited subjects participated.

\section{Controls}

The control group consisted of 30 female medical nurses with a mean (range) age of $41 \cdot 7$ (26-60) years and duration of employment $8.2(0.3-28)$ years from the blood centres at two hospitals and some occupational health service centres in the same area.

The work of the control group was physically light and varied, with demands of skilfulness in precision, hand mobility, and tactile sensitivity. The controls had no occupational exposure to vibrations from hand held tools or to mercury. From now on, when not considered separately, dentists and hygienists are referred to as the exposed groups, dental assistants and controls as the non-exposed ones.

\section{QUESTIONNAIRE}

Two standardised forms were used in the interviews of the participants by a physiotherapist and a technician, both experienced.

One form contained questions related to work that concerned working hours a day, years of employment, and use of ultrasonic devices. Also, smoking habits (current, cigarettes a day; ex-smokers; never-smokers; snuff takers), rheumatoid arthritis, and diabetes were asked for. No diabetic was encountered. One subject (a control) had a history of rheumatoid arthritis, but no symptoms and signs at the time of examination. Questions about symptoms that related to vibration of the arms or hands (sensorineural and vascular) were asked, and the subjects were classified (table 5). Subjective symptoms (such as nightly numbness in the median nerve region of the hand) related to carpal tunnel syndrome were asked for, and any surgery for that syndrome was noted.

Symptoms (ache, pain, discomfort) thought to originate from the musculoskeletal system during the past 12 months and the previous seven days, and sick leave because of these during the preceding 12 months were determined by a form based on three standardised Nordic questionnaires (general, and specific for neck and shoulders). ${ }^{14}$

\section{TEST OF NEUROMUSCULAR FUNCTION Vibrogram}

Tests were performed by the method of Lundborg et al. ${ }^{15-17}$ The perception thresholds were recorded at different frequencies of vibration $(8,16,31.5,65,125,250$, and
$500 \mathrm{~Hz}$ ). The frequencies were automatically changed through this frequency range. On the basis of these perception thresholds, a vibrogram curve (tactilogram) was obtained. Vibrograms were recorded from the second and fifth fingers of both hands, more than two hours after the end of exposure to vibration.

\section{Sensibility index}

A sensibility index (SI) was used as a measure of sensitivity disturbance, according to a method described by Lundborg et al. ${ }^{17}$ The index was obtained by dividing the area under the vibrogram curve by the median of the areas under the control's curves (no age adjustment).

In some situations, depending upon the relevance of a particular issue, an SI-sum was calculated by addition of the SIs for individual fingers, either for the dominant and non-dominant hands separately, or for both hands together.

\section{Two point discrimination (2PD)}

Discriminatory tactile sensation was determined as described by Moberg. ${ }^{18} 19$ The test was performed on the index and little fingers of both hands.

\section{Tactile identification test}

Tests were performed according to a method described by Sperling and Jonsson. ${ }^{20}$ Discrimination between six different shapes was tested blindly at four different sizes.

\section{Muscular strength}

Dynamometer tests (Martin vigorimeter, Tuttlingen, Germany) were performed in triplicate (maximal values used). The medium rubber bulb (diameter $4.5 \mathrm{~cm}$ ) was used to measure the maximum grip strength of each hand, the small bulb $(4 \mathrm{~cm})$ to test key and pinch grip involving the thumb and the index and the middle fingers. The tests were performed in a standardised position with the forearm supported.

\section{Manual performance}

The dominant hand was tested. The subjects had to pick up and transfer a selected set of small sized dental equipment, 28 pieces (burs, matrix band, grind discs, dowels, etc) with a pair of tweezers from one petri-glass cup to another. The time was measured; the best of three attempts was used.

\section{MONITORING OF MERCURY}

Mercury concentrations in whole blood $(\mathrm{HgB})$, and plasma (HgP) and mercury and creatinine in urine $(\mathrm{HgU})$ were determined as already described. ${ }^{12}$

\section{STATISTICS}

The perception thresholds of vibrotactile function could be obtained only for values up to $150 \mathrm{~dB}$. Thresholds greater than that give censored readings with $150 \mathrm{~dB}$ as the recorded values (mostly at frequencies of 125,250 , and $500 \mathrm{~Hz}$ ). When censored readings occurred we have presented medians 
Table 1 Results of vibrograms in the index and little fingers of the dominant and non-dominant hands of dentists, dental hygienists, dental assistants, and controls; $n=30$ in each group

\begin{tabular}{|c|c|c|c|c|c|c|c|c|c|}
\hline \multirow[b]{3}{*}{ Finger Side No } & \multirow[b]{3}{*}{$\begin{array}{l}\text { Frequency } \\
(\mathrm{Hz})\end{array}$} & \multicolumn{8}{|l|}{ Threshold } \\
\hline & & \multicolumn{2}{|l|}{ Dentists } & \multicolumn{2}{|c|}{ Dental hygienists } & \multicolumn{2}{|c|}{ Dental assistants } & \multicolumn{2}{|l|}{ Controls } \\
\hline & & $\begin{array}{l}\text { Mean or } \\
\text { median } \\
(d B)\end{array}$ & $\begin{array}{l}>150 \mathrm{~dB} \\
(n)\end{array}$ & $\begin{array}{l}\text { Mean or } \\
\text { median } \\
(d B)\end{array}$ & $\begin{array}{l}>150 \mathrm{~dB} \\
(n)\end{array}$ & $\begin{array}{l}\text { Mean or } \\
\text { median } \\
(d B)\end{array}$ & $\begin{array}{l}>150 \mathrm{~dB} \\
(n)\end{array}$ & $\begin{array}{l}\text { Mean or } \\
\text { median } \\
(d B)\end{array}$ & $\begin{array}{l}>150 \mathrm{~dB} \\
(n)\end{array}$ \\
\hline $\begin{array}{l}\text { Dominant: } \\
\text { Index }\end{array}$ & $\begin{array}{l}8 \\
16 \\
31 \cdot 5 \\
63 \\
125 \\
250 \\
500 \\
\text { SI (range) }\end{array}$ & $\begin{array}{c}99 \cdot 5^{\star} \\
106 \cdot 8^{\star} \\
113 \cdot 7^{\star} \\
112 \cdot 3^{\star} \\
110 \cdot 0^{\star} \\
115 \cdot 0 \\
130 \cdot 0 \\
0 \cdot 87^{\star}\end{array}$ & $\begin{array}{l}(0) \\
(0) \\
(5) \\
(0 \cdot 34-1 \cdot 22)\end{array}$ & $\begin{array}{l}100 \cdot 3^{\star \star} \\
106 \cdot 7^{\star} \\
111 \cdot 2 \\
111 \cdot 0 \\
107 \cdot 5 \\
115 \cdot 0 \\
130 \cdot 0 \\
0 \cdot 89\end{array}$ & $\begin{array}{l} \\
(1) \\
(2) \\
(8) \\
(0 \cdot 26-1 \cdot 19)\end{array}$ & $\begin{array}{c}99.0^{\star \star} \\
105 \cdot 2 \\
111.8 \\
110.0 \\
105.0 \\
110.0 \\
127.5 \\
0.93 \dagger\end{array}$ & $\begin{array}{l} \\
(0) \\
(0) \\
(4) \\
(0 \cdot 46-1 \cdot 22)\end{array}$ & $\begin{array}{c}94 \cdot 7 \\
102 \cdot 5 \\
108 \cdot 5 \\
107 \cdot 7 \\
105 \cdot 0 \\
110 \cdot 0 \\
130 \cdot 0 \\
0.99\end{array}$ & $\begin{array}{l}(0) \\
(0) \\
(1) \\
(0 \cdot 73-1 \cdot 39)\end{array}$ \\
\hline Little & $\begin{array}{l}8 \\
16 \\
31 \cdot 5 \\
63 \\
125 \\
250 \\
500 \\
\text { SI (range) }\end{array}$ & $\begin{array}{c}98 \cdot 8 \\
104 \cdot 8 \\
112 \cdot 3^{\star} \\
115 \cdot 3^{\star} \\
110 \cdot 0^{\star} \\
115 \cdot 0^{\star} \\
140 \cdot 0^{\star} \\
0 \cdot 87^{\star}\end{array}$ & $\begin{array}{l}(0) \\
(3) \\
(4) \\
(0 \cdot 33-1 \cdot 14)\end{array}$ & $\begin{array}{c}97 \cdot 5 \\
105 \cdot 8 \\
113 \cdot 0 \\
115 \cdot 0 \\
110 \cdot 0 \\
112 \cdot 5 \\
132 \cdot 5 \\
0.87\end{array}$ & $\begin{array}{l}(1) \\
(4) \\
(7) \\
(0 \cdot 26-1 \cdot 26)\end{array}$ & $\begin{array}{c}97 \cdot 7 \\
103 \cdot 8 \\
109 \cdot 7 \\
109 \cdot 2 \\
105 \cdot 0 \\
107 \cdot 5 \\
130 \cdot 0 \\
0.99\end{array}$ & $\begin{array}{l} \\
(0) \\
(1) \\
(3) \\
(0 \cdot 43-1 \cdot 43)\end{array}$ & $\begin{array}{c}95 \cdot 5 \\
102 \cdot 3 \\
109.5 \\
110.7 \\
105 \cdot 0 \\
110.0 \\
130.0 \\
0.98\end{array}$ & $\begin{array}{l}(0) \\
(0) \\
(2) \\
(0 \cdot 67-1 \cdot 24)\end{array}$ \\
\hline $\begin{array}{l}\text { Non-dominant } \\
\text { Index }\end{array}$ & $\begin{array}{l}\quad 8 \\
16 \\
31 \cdot 5 \\
63 \\
125 \\
250 \\
500 \\
\text { SI (range) }\end{array}$ & $\begin{array}{c}97 \cdot 3 \\
104.8 \\
110.7 \\
110 \cdot 7 \\
108.5^{\star} \\
115.0 \\
130.0 \\
0.92^{\star}\end{array}$ & $\begin{array}{l}(0) \\
(1) \\
(3) \\
(0 \cdot 49-1 \cdot 15)\end{array}$ & $\begin{array}{c}97 \cdot 9 \\
105 \cdot 0 \\
110.7 \\
109.7 \\
107 \cdot 6^{\star} \\
115 \cdot 0 \\
135 \cdot 0 \\
0.93\end{array}$ & $\begin{array}{l}(0) \\
(0) \\
(3) \\
(0 \cdot 63-1 \cdot 32)\end{array}$ & $\begin{array}{c}95 \cdot 3 \\
103 \cdot 5 \\
108 \cdot 0 \\
107 \cdot 0 \\
103 \cdot 2 \\
105 \cdot 0 \\
127 \cdot 5 \\
1 \cdot 00\end{array}$ & $\begin{array}{l}(0) \\
(0) \\
(2) \\
(0 \cdot 37-1 \cdot 20)\end{array}$ & $\begin{array}{c}94 \cdot 8 \\
101 \cdot 8 \\
108 \cdot 0 \\
107 \cdot 2 \\
103 \cdot 5 \\
110 \cdot 0 \\
130 \cdot 0 \\
1 \cdot 00\end{array}$ & $\begin{array}{l}(0) \\
(0) \\
(0) \\
(0 \cdot 70-1 \cdot 27)\end{array}$ \\
\hline Little & $\begin{array}{l}8 \\
16 \\
31 \cdot 5 \\
63 \\
125 \\
250 \\
500 \\
\text { SI (range) }\end{array}$ & $\begin{array}{c}97 \cdot 8^{\star} \\
105 \cdot 5^{\star} \\
111 \cdot 7 \\
112 \cdot 0 \\
105 \cdot 0 \\
115 \cdot 0 \\
130 \cdot 0 \\
0.91\end{array}$ & $\begin{array}{l}(0) \\
(1) \\
(4) \\
(0 \cdot 46-1 \cdot 12)\end{array}$ & $\begin{array}{c}97 \cdot 3 \\
105 \cdot 2^{\star} \\
111 \cdot 3 \\
111 \cdot 3 \\
110 \cdot 0^{\star} \\
115 \cdot 0^{\star} \\
132 \cdot 5 \\
0 \cdot 89^{\star}\end{array}$ & $\begin{array}{l}(1) \\
(1) \\
(3) \\
(0 \cdot 39-1 \cdot 20)\end{array}$ & $\begin{array}{c}95 \cdot 3 \\
103 \cdot 8 \\
109 \cdot 3 \\
109 \cdot 5 \\
105 \cdot 0 \\
110 \cdot 0 \\
125 \cdot 0 \\
0.97\end{array}$ & $\begin{array}{l}(0) \\
(0) \\
(2) \\
(0 \cdot 49-1 \cdot 22)\end{array}$ & $\begin{array}{c}94 \cdot 1 \\
101 \cdot 4 \\
108 \cdot 8 \\
110 \cdot 0 \\
105 \cdot 0 \\
110 \cdot 0 \\
130 \cdot 0 \\
0.98\end{array}$ & $\begin{array}{l}(0) \\
(0) \\
(0) \\
(0 \cdot 63-1 \cdot 34)\end{array}$ \\
\hline
\end{tabular}

Medians in italics. Tests on dental personnel $v$ controls; when means are given, $t$ tests were used and when medians, two sample rank sum tests: ${ }^{\mathrm{P}}<0.05, \star \star \mathrm{P}<0.01, \star \star \star \mathrm{P}<0.001$. Dominant $v$ non-dominant hands were tested by paired $t$ tests; $+P<0.05$. SI $=$ sensibility index.

(together with frequencies), arithmetic means are otherwise given. We tested differences between groups by means of Gehan's test ${ }^{21}$ (generalised Wilcoxon's two sample rank sum test) that handles censored readings; $t$ tests were used otherwise.

To compare the occurrence of musculoskeletal symptoms among dental personnel with controls, we used a logistic regression with adjustment for age. Comparisons of SI between groups with or without musculoskeletal symptoms in various regions during the past seven days, and vascular or sensorineural symptoms (graded 0-4), 2PD (2-8 $\mathrm{mm}$ ) were tested by the Wilcoxon's two sample rank sum test. Muscular strength of the hands and manual performance were nearly normally distributed, and comparisons were made by two sample $t$ tests. Differences between groups, for the proportion of errors in the tactile discrimination test, were tested by means of $Z$ tests.

We studied associations between continuous variables like age, perception thresholds, SI, manual performance, muscular strength of the hands, $\mathrm{HgB}, \mathrm{HgP}$ and $\mathrm{HgU}$ by linear regression. To test individual differences in threshold values for the dominant hand $v$ the non-dominant hand, we used paired $t$ tests. Fisher's exact test was used to test for associations between smoking and vascular or sensorineural symptoms. The significance level used was $5 \%$; two tailed tests were used.

\section{Results}

\section{NEUROMUSCULAR FUNCTION}

Vibrogram

The dentists and dental hygienists had, in comparison with the controls, increased perception thresholds for many different frequencies (table 1). In the control group, there was no association between age and the thresholds for the various frequencies in the different fingers. Thus, no age correction of the vibrograms of the dental personnel was performed.

In the index finger of the dominant hand, the dentists had significantly increased perception thresholds for the frequencies 8,16 , 31.5 , and $125 \mathrm{~Hz}$, and for the little finger of the same hand for $63,125,250$, and $500 \mathrm{~Hz}$ (table 1). In the non-dominant hand, the index finger had significantly increased thresholds for $125 \mathrm{~Hz}$, and the little finger for 8 and $16 \mathrm{~Hz}$. Dental hygienists had significantly increased thresholds for the index finger of the dominant hand for 8 and $16 \mathrm{~Hz}$. In the non-dominant hand, the index finger had significantly increased thresholds for $125 \mathrm{~Hz}$, and in the little finger for 16, 125, and $250 \mathrm{~Hz}$. Dental assistants differed significantly from the controls only in the index finger of the dominant hand for $8 \mathrm{~Hz}$.

When the vibrograms of the dominant and the non-dominant hand were compared for the different frequencies, the dominant hand constantly has higher average perception levels than the other hand, for all the different 
Table 2 Test of two point discrimination (2PD), tactile identification, manual performance among dentists, dental hygienists, dental assistants, and controls; $n=30$ in each group

\begin{tabular}{|c|c|c|c|c|c|c|c|}
\hline \multirow[b]{3}{*}{ Group } & \multicolumn{4}{|c|}{$\begin{array}{l}\text { Two point discrimination } \\
\text { (subjects with } 2 P D>4 \mathrm{~mm} \text { ) }\end{array}$} & \multirow{2}{*}{\multicolumn{2}{|c|}{$\begin{array}{l}\text { Tactile identification } \\
\text { (mean error proportion) }\end{array}$}} & \multirow[b]{3}{*}{$\begin{array}{l}\text { Manual performances } \\
\text { (mean SD) }\end{array}$} \\
\hline & \multicolumn{2}{|c|}{$\begin{array}{l}\text { Dominant } \\
\text { finger }\end{array}$} & \multicolumn{2}{|c|}{$\begin{array}{l}\text { Non-dominant } \\
\text { finger }\end{array}$} & & & \\
\hline & $I I$ & $V$ & $I I$ & $V$ & $\begin{array}{l}\text { Dominant } \\
\text { hand }\end{array}$ & $\begin{array}{l}\text { Non-dominant } \\
\text { hand }\end{array}$ & \\
\hline $\begin{array}{l}\text { Dentists } \\
\text { Dental hygienists } \\
\text { Dental assistants } \\
\text { Controls }\end{array}$ & $\begin{array}{l}3 \\
0 \\
3 \\
0\end{array}$ & $\begin{array}{l}4 \\
3 \\
2 \\
2\end{array}$ & $\begin{array}{l}2 \\
0 \\
0 \\
0\end{array}$ & $\begin{array}{l}5 \\
2 \\
2 \\
3\end{array}$ & $\begin{array}{l}0 \cdot 16 \\
0 \cdot 20 \\
0 \cdot 20 \\
0 \cdot 20\end{array}$ & $\begin{array}{l}0 \cdot 19 \\
0 \cdot 21 \\
0 \cdot 23 \\
0 \cdot 18\end{array}$ & $\begin{array}{l}45 \cdot 5(11 \cdot 2) \dagger \\
42 \cdot 4(9 \cdot 0) \dagger \\
38 \cdot 3(5 \cdot 6)^{\star \star} \\
43 \cdot 6(9 \cdot 4)\end{array}$ \\
\hline
\end{tabular}

Dental personnel groups $v$ controls $\left(t\right.$ test; ${ }^{\star} P<0.05,{ }^{\star \star} P<0.01,{ }^{\star \star \star} P<0.001$ ); dentists and dental hygienists $v$ dental assistants: $+P \leqslant 0.05$.

Table 3 Test of muscular hand strength among dentists, dental hygienists, dental assistants, and controls; $n=30$ in each group

\begin{tabular}{|c|c|c|c|c|c|c|}
\hline & \multicolumn{6}{|c|}{ Muscular strength (bar: mean (SD)) } \\
\hline & \multicolumn{2}{|l|}{ Full hand grip } & \multicolumn{2}{|l|}{ Pinch grip } & \multicolumn{2}{|l|}{ Key grip } \\
\hline & Dominant & Non-dominant & Dominant & Non-dominant & Dominant & Non-dominant \\
\hline $\begin{array}{l}\text { Dentists } \\
\text { Dental hygienists } \\
\text { Dental assistants } \\
\text { Controls }\end{array}$ & $\begin{array}{l}0 \cdot 86^{\star \star \star}+(0 \cdot 25) \\
0 \cdot 87^{\star \star \star}+(0 \cdot 17) \\
0.97^{\star \star}(0 \cdot 17) \\
1 \cdot 11(0 \cdot 18)\end{array}$ & $\begin{array}{l}0.83^{\star \star \star}+(0 \cdot 20) \\
0.91^{\star}(0 \cdot 20) \\
0.95^{\star}(0 \cdot 20) \\
1.03(0 \cdot 19)\end{array}$ & $\begin{array}{l}0.61(0.11) \\
0.57 \star(0.08) \\
0.62(0.05) \\
0.62(0.08)\end{array}$ & $\begin{array}{l}0.58(0.09) \\
0.59(0.08) \\
0.61(0.06) \\
0.61(0.10)\end{array}$ & $\begin{array}{l}0.51^{\star \star}(0.10) \\
0.51^{\star}(0.11) \\
0.54(0.08) \\
0.57(0.06)\end{array}$ & $\begin{array}{l}0.50^{\star \star}+(0.09) \\
0.49^{\star \star \star}+(0.09) \\
0.54(0.07) \\
0.56(0.06)\end{array}$ \\
\hline
\end{tabular}

Dental personnel groups $v$ controls $\left(t\right.$ test; $\left.{ }^{\star} \mathrm{P}<0.05,{ }^{\star \star} \mathrm{P}<0.01,{ }^{\star \star \star} \mathrm{P}<0.001\right)$; dentists and dental hygienists $v$ dental assistants: $\dagger \mathrm{P}<0.05 ; 1$ bar $=100 \mathrm{kPa}$.

groups. Interestingly, the differences, are more apparent for both the dentists and the dental hygienists, and for all frequencies, than for the dental assistants and the controls, although not significantly different. For the controls the differences are minor.

\section{Sensibility index}

There were no significant differences in SIs for either hand between the different smoking groups with and without exposure to vibration.

For the dentists there was an impaired SI for all fingers tested on the dominant hand, and for the index finger on the non-dominant one, compared with the controls (table 1). Among the dental hygienists, an impairment was found for the little fingers of both hands. Also among the dentists, there was a slight, but significant decrease of SI in the dominant hand (sum of both fingers) with increasing duration of exposure. One year of exposure was associated with an average SI decrease of $0.018(P=0.017)$. No such significant association was found in the non-dominant hand, nor in any of the hygienists' hands. There was a tendency for the dominant hand to have lower SI than the non-dominant one, but the differences were not significant for the dentists or the dental hygienists.

\section{Two point discrimination}

There were no significant differences between the groups (table 2). For the dentists there were significant associations between a high 2PD ( $>4 \mathrm{~mm}$ ) and a low SI (for the index finger of the dominant hand average $S I=0.60$ at $>4 \mathrm{~mm} v 0.90$ at $\leqslant 4 \mathrm{~mm}, P=0.049$; and for the little fingers; dominant hand $0.70 v$ $0.89, \mathrm{P}=0.035$; non-dominant $0.69 v 0.95$, $\mathrm{P}=0.0022$; for the non-dominant index finger there was a non-significant trend). The other subgroups showed no significant effects.
Tactile identification test

There were no significant differences between the groups (table 2).

\section{Muscular strength}

Muscular strength was significantly lower among the dentists and the hygienists than among dental assistants, who in turn had lower values than the controls (table 3 ). There were significant associations between the full hand grip and the SI of the little finger of the dominant hand within the dentist group ( $P=$ 0.014 ), and with SI of the index finger of the non-dominant hand in the hygienists $(P=$ 0.041 ). Also, among the dentists, the pinch grip was significantly associated with the SI for the index finger of the dominant hand $(P=0.025)$. The other subgroups had no significant associations. No such significant association was seen for the key grip.

\section{Manual performance}

The dentists, hygienists, and controls did not differ significantly from each other, whereas the dental assistants had a significantly better performance (table 2). For the dentists, a higher SI for the index finger of the dominant hand displayed a borderline association with a better performance test $(P=0.054)$; an SI increase of $0 \cdot 1$ corresponded to an average decrease of the manual performance test of two seconds; total test time was about 40 seconds.

\section{SYMPTOMS}

\section{Musculoskeletal symptoms}

The dentists and the dental hygienists had, in comparison with the controls, higher frequencies of ache, pain, or discomfort within the past seven days in the neck and upper limbs (table 4). Symptoms in the past 12 months showed the same general pattern (not in 
Table 4 Frequencies of musculoskeletal symptoms during the previous seven days among dentists, dental hygienists, dental assistants, and controls: $n=30$ in each group

\begin{tabular}{llllllllll}
\hline & \multicolumn{1}{l}{ Muscuoskeletal symptoms } & & & & \\
\cline { 2 - 10 } Group & Neck & Shoulders & Elbows & $\begin{array}{l}\text { Hands or } \\
\text { wrists }\end{array}$ & $\begin{array}{l}\text { Upper } \\
\text { back }\end{array}$ & $\begin{array}{l}\text { Lower } \\
\text { back }\end{array}$ & Hips & $\begin{array}{l}\text { Feet or } \\
\text { ankles }\end{array}$ \\
\hline Dentists & 11 & $14^{\star \star}$ & 3 & $9^{\star}$ & 5 & 10 & 3 & 2 & 3 \\
Dental hygienists & $15^{\star}$ & $12^{\star}$ & $6^{\star \star}$ & $10^{\star}$ & 6 & 3 & 2 & 2 & 0 \\
Dental assistants & 4 & 8 & 0 & 0 & 4 & 6 & 1 & 1 & 0 \\
Controls & 6 & 5 & 0 & 3 & 1 & 4 & 2 & 2 & 2 \\
\hline
\end{tabular}

Dental personnel $v$ controls with a logistic regression model, with adjustment for age, or $Z$ test: ${ }^{\star} \mathrm{P}<0.05,{ }^{\star \star} \mathrm{P}<0.01$.

table). There were no significant associations between reported symptoms of the neck, shoulders, or elbows in the past seven days and the corresponding SI-sums for the tested fingers in the entire group or in any of the subgroups. The shoulders and elbows of the dominant side and the non-dominant side were tested separately.

Among the dentists the average SI-sum was only slightly lower among those with neck symptoms than in those without $(3.43 v 3.63$, NS); within the hygienist group those with neck symptoms had a slightly higher SI-sum than those without ( $3.63 v 3.54$; NS). The same pattern was noted for symptoms of the shoulders and elbows (NS).

There were no significant associations between symptoms of the neck or shoulders and grip strength, manual performance, or 2PD.

Carpal tunnel syndrome was found in only one dentist and one dental hygienist (both in the dominant hand). Both had had surgery, and the dental hygienist had a relatively high SI $(0 \cdot 83)$, the still symptomatic dentist a low one $(0.53)$ in the relevant index finger. In the dentists the dominant hand showed a significant association between hand symptoms during the past seven days and the SI-sum for the corresponding side $(1.41 v 1.85, \mathrm{P}=0.0015)$. The same association was found for the nondominant hand $(1.43 v 1.90, \mathrm{P}=0.013)$. Among the dental hygienists there was the same trend (NS). In the non-exposed groups there was no such association. In the dentists, there were some significant associations between hand symptoms and grip strength (dominant side, $P=0.0083$; non-dominant, $\mathrm{P}=0.0050$ ), and 2PD (dominant side, $\mathrm{P}=0.019)$.

Vascular symptoms

Vascular symptoms were found in 19 women (table 5). There were no significant associa- tions between smoking and vascular symptoms. No significant differences in the prevalence of vascular symptoms between the subgroups were found. There were no significant associations between duration of exposure to vibration and vascular symptoms.

Vascular symptoms showed a significant association with a low SI-sum (all four fingers) among the dental assistants (with symptoms, SI-sum $3.28 \quad(\mathrm{n}=6)$; without symptoms, $4.05(\mathrm{n}=24) ; \mathrm{P}=0.017)$, but not in the controls, or the groups exposed to vibration.

\section{Sensorineural symptoms}

Eighteen subjects had sensorineural symptoms, $27 \%$ among both the dentists and hygienists, $3 \%$ in both the dental assistants and controls (table 5). There were no significant associations between age and smoking and occurrence of sensorineural symptoms Among the dentists, however, there was an association between increased age and sensorineural symptoms $(P=0 \cdot 048)$, not present in any other subgroup.

A combination of persistent numbness, reduced manual dexterity, and reduced grip (stage 4) was found in seven dentists and five dental hygienists, but in neither the dental assistants nor the controls (table 5). Both dentists and hygienists differed significantly from the unexposed groups.

Among the dentists those with any sensorineural symptoms showed an average SIsum for both hands of $3 \cdot 19(\mathrm{n}=8)$, and those without symptoms 3.69 ( $n=22 ; P=0.024)$. There was no significant difference in any of the other two groups.

In the dentists only there was a significant association between musculoskeletal symptoms of the hands during the past seven days and sensorineural symptoms $(P=0.0031)$ Thus nine dentists had musculoskeletal symptoms, and six of those had sensorineura

Table 5 Frequencies of vascular and sensorineural symptoms in arms or hands among dentists, dental hygienists, dental assistants, and controls; $n=30$ in each group

\begin{tabular}{|c|c|c|c|c|c|c|c|c|c|c|}
\hline \multirow[b]{3}{*}{ Group } & \multicolumn{10}{|c|}{ Symptoms } \\
\hline & \multicolumn{5}{|c|}{ Vascular (stage $\ddagger$ ) } & \multicolumn{5}{|c|}{ Sensorial (stage $\mathbb{1})$} \\
\hline & 0 & 1 & 2 & 3 & 4 & 0 & 1 & 2 & 3 & 4 \\
\hline $\begin{array}{l}\text { Dentists } \\
\text { Dental hygienists } \\
\text { Dental assistants } \\
\text { Controls }\end{array}$ & $\begin{array}{l}24 \\
26 \\
24 \\
27\end{array}$ & $\begin{array}{l}4 \\
2 \\
5 \\
2\end{array}$ & $\begin{array}{l}1 \\
0 \\
0 \\
1\end{array}$ & $\begin{array}{l}1 \\
2 \\
0 \\
0\end{array}$ & $\begin{array}{l}0 \\
0 \\
1 \\
0\end{array}$ & $\begin{array}{l}22^{\star \star} \dagger \\
22^{\star \star} \dagger \\
29 \\
29\end{array}$ & $\begin{array}{l}0 \\
2 \\
0 \\
0\end{array}$ & $\begin{array}{l}1 \\
0 \\
1 \\
1\end{array}$ & $\begin{array}{l}0 \\
1 \\
0 \\
0\end{array}$ & $\begin{array}{l}7 \\
5 \\
0 \\
0\end{array}$ \\
\hline
\end{tabular}

Dental personnel $v$ controls: $\star \star ~ P<0.01$; dentists and hygienists $v$ dental nurses: $\dagger \mathrm{P}<0.01$, by the Wilcoxon's two sample rank sum test. $\ddagger$ Stage: $0=$ no symptoms, $1=$ episodic blanching of one or more finger tips, $2=$ episodic blanching of one or more fingers for test. $\ddagger$ Stage: $0=$ no symptoms, $1=$ episodic blanching of one or more finger tips, $2=$ episodic blanching of one or more fingers for
$\leqslant 15 \mathrm{~min}$, mostly during winter, $3=$ attacks of blanching affecting most or all fingers $>15 \mathrm{~min}$, even during summer, $4=$ as in stage 3, symptoms every day, with trophic skin changes in the finger tips. (Stage: $0=$ no symptoms, $1=$ with (tingling) paraesthesia during and shortly after exposure to vibrations, $2=$ as in stage 1 , with (tingling) paraesthesia at night, $3=$ with (tingling) paraesthesia or numbness most of the time, $4=$ persistent numbness, reduced manual dexterity and grip function. 
Table 6 Mercury concentrations (mean (SD; range)) in urine ( $\mathrm{HgU})$, plasma $(\mathrm{HgP})$, and blood (HgB) for dentists, dental hygienists, dental assistants, and controls

\begin{tabular}{|c|c|c|c|c|c|c|}
\hline \multirow[b]{3}{*}{ Group } & \multicolumn{6}{|c|}{ Mercury concentrations } \\
\hline & \multicolumn{2}{|c|}{$H g U$} & \multicolumn{2}{|c|}{$H g B$} & \multicolumn{2}{|c|}{$H g P$} \\
\hline & $n$ & ( $\mu g / g$ creatinine $) \dagger$ & $n$ & $(\mu g / l) \ddagger$ & $n$ & $(\mu g / l) \ddagger$ \\
\hline $\begin{array}{l}\text { Dentists } \\
\text { Dental hygienists } \\
\text { Dental assistants } \\
\text { Referents }\end{array}$ & $\begin{array}{l}29 \\
27 \\
30 \\
28\end{array}$ & $\begin{array}{l}3.4(2 \cdot 1 ; 1 \cdot 1-11) \\
3 \cdot 6(1 \cdot 9 ; 0 \cdot 72-8 \cdot 0) \\
5.5(3 \cdot 8 ; 1 \cdot 3-18) \\
3.5(2 \cdot 3 ; 0 \cdot 76-10)\end{array}$ & $\begin{array}{l}30 \\
29 \\
30 \\
29\end{array}$ & $\begin{array}{l}3.5(1.2 ; 1.4-6.5) \\
2.9(0.9 ; 1.2-4.9) \\
3.4(1.3 ; 1.4-6.5) \\
2.9(1.5 ; 0.70-7.8)\end{array}$ & $\begin{array}{l}30 \\
29 \\
30 \\
29\end{array}$ & $\begin{array}{l}1.5(0.8 ; 0.6-4.2) \\
2.9(0.9 ; 0.5-2.7) \\
2.0(1.0 ; 0.8-5.5) \\
1.6(1.0 ; 0.4-5.2)\end{array}$ \\
\hline
\end{tabular}

Dental personnel group $v$ controls: $\mathrm{P}<0.05$ ( $t$ test)

$\dagger 1 \mu \mathrm{g} / \mathrm{g}$ creatinine $=0.56 \mathrm{nmol} / \mu \mathrm{mol}$ creatinine; $\ddagger 1 \mu \mathrm{g} / 1=5.0 \mathrm{nmol} / 1$.

symptoms as well. Among the remaining 21 dentists without musculoskeletal symptoms, only two had sensorineural symptoms.

\section{MONITORING OF MERCURY}

On the whole, there was a significant increase of $\mathrm{HgB}$ with age $(P=0.012)$; neither $\mathrm{HgP}$ nor $\mathrm{HgU}$ showed such a trend (not in table). None of the subgroups separately showed a significant increase of $\mathrm{HgB}$ with age. Only U$\mathrm{Hg}$ in dental assistants was significantly different (higher) from the controls (table 6).

Neither vibrograms (sum of all four SIs in both hands in each person), nor 2PD, tactile discrimination test (hands separately), manual performance (dominant hand), or strength (hands separately) showed any significant associations with $\mathrm{HgB}, \mathrm{HgP}$ or $\mathrm{HgU}$.

\section{Discussion}

The most interesting findings in our study are the increased vibrotactile perception thresholds (at low and high frequencies), the decreased strength, particularly in the dominant hand, and the impairment in the manual performance test, for the groups exposed to vibration. The group with the longest duration of exposure-the dentists-showed more frequent and obvious sensorineural symptoms, impairment of discriminatory tactile sensation, and associations between the vibrotactile sensibility and grip strength, motor performance, $2 \mathrm{PD}$, and the occurrence of sensorineural and other symptoms of the hands.

The study was a cross sectional one. Thus, the possibility of a healthy worker selection must be considered: it is possible that some dentists and hygienists may have left the professions because of musculoskeletal or neurological symptoms.

The controls without vibration or exposure to mercury were selected on the basis of similar socioeconomic conditions and varied work postures. It turned out, however, that an important fraction of the controls had work with relatively high workload on the hands, which may have caused an underestimate of the risk of hand symptoms in the other groups.

All methods but the mercury determinations had a subjective component, which may have made it impossible to observe minor effects. The reproducibility of the vibrogram performance was good. The vibrograms, however, at the highest frequencies $(125,250$, and
$500 \mathrm{~Hz}$ ) sometimes reached the maximum level of $150 \mathrm{~dB}$, above which it was not technically possible to record. Thus, there is a risk that vibrotactile neuropathies are underestimated in such cases.

The sensorineural and vascular symptoms were scored according to schemes routinely used for a long time at the department, and which, when used in parallel with the stagings suggested by Bramner et al and Gemne et al in a follow up study of the present groups, ${ }^{22} 23$ were found to give very similar results (unpublished data). The screening questionnaires for supposed musculoskeletal symptoms of the hands may also record neuropathies and circulatory disturbances.

In the dentists, there was a decrease of vibrotactile perception with increasing duration of vibration exposure. We did not adjust for age. In some other studies, there was an age effect, ${ }^{172425}$ mainly at high frequencies, ${ }^{26}$ but the present effect associated with vibration occurred mainly at low ones. We did not see an age effect in the groups without exposure to vibration, probably because the age effect is less pronounced in women than in men (due to occupational exposure and other vibrational exposure), and occurs mainly at higher ages.

There were impairments of vibrotactile perception in both the dominant and-although less pronounced-non-dominant hands. In the dentists, however, the effect in the non-dominant hand may be due to firmly holding crowns, stabilisation splints, and removable orthodontic appliances with this hand, and by using vibrating tools during adjustments before installation. A similar pattern has been recorded in dental technicians. ${ }^{7}$ The present effect in the little finger of the dominant hand may be due to exposure to vibration, as a grip that involves all five fingers is often used during work with low speed hand pieces and ultrasonic devices in the lingual area of the lower jaw.

Our results are in accordance with earlier findings of vibrotactile perceptual disturbances in small studies of dentists ${ }^{15}$ and physiotherapists. ${ }^{27}$ The physiotherapists use ultrasonic therapeutic devices, although with different energy characteristics than the present ultrasonic scalers.

We found that the grip forces were lower among the groups exposed to vibration. Impairment was noted in the full hand and key grips. Decreased muscle strength has previously been found in lumberjacks exposed to 
vibration, particularly in those subjectively most affected by vibration disease. ${ }^{28} 29$ Workers exposed to vibrations often complain of decreased muscular force. ${ }^{29}$ It seems that this is a constant phenomenon, not only present during work. ${ }^{28}$ The impaired muscle function in the full hand grip, which also engages the local muscles of the hand, may be based on an injury to muscle tissue, nerve tissue, or a combination of both induced by vibration. Experimental studies have shown that vibration may damage nerve fibres ${ }^{30} 31$ and infraneural microvessels ${ }^{32}$ as well as muscle fibres. $^{33}$

The relation between impaired SI and decreased muscle strength in the full hand grip may support the theory that impaired muscle function is secondary to sensibility disturbance. One cannot exclude, however, a direct injury to hand muscles induced by vibration. Recent experimental studies have shown degenerative phenomena of various degrees in muscles in the feet of rats exposed to vibration. ${ }^{33}$

There is a demand for manual dexterity among dental personnel. Thus it is reasonable to compare the results of the manual performance test mainly within these three groups. The dental assistants had a better manual performance than the other two groups. This might be due to a deterioration of the manual performance induced by vibration in the exposed groups, which is supported by the association between SI and manual performance. The difference is probably not due to musculoskeletal factors as there was no association between such symptoms and manual performance.

Our results show no significant differences in the 2PD tests between the groups. This corresponds with the work of Lundborg et al. ${ }^{15}{ }^{16}$ Changes in 2PD are known to occur only at an advanced stage in a nerve lesion, and usually involve degeneration and regeneration of fibres. For the dentists, there was an association between a low SI and high 2PD. The pathophysiological mechanisms involved in peripheral neural changes induced by vibration are not fully understood. ${ }^{1}$ Damage induced by vibration has been seen in the microvascular structures of the nerves, ${ }^{32}$ as well as in the nerve fibres..$^{30} 3134$ High frequency vibrations from hand held tools may damage the mechanoreceptive units. ${ }^{35}$

Only two cases of carpal tunnel syndrome were encountered in a dentist as well as in a hygienist who had normal vibrograms. Thus, carpal tunnel syndrome induced by work was not the cause of the sensory disturbances. There was no association between the exposure to vibration and gross vascular symptoms, which is in accordance with earlier findings. ${ }^{4}$

The work of the dental personnel includes static muscle load with rotation and flexion of the cervical spine and flexion of the elbow. Also, some operations involve repetitive forceful hand grips. Accordingly, many hygienists and dentists reported musculoskeletal symptoms from the neck, shoulders, arms, and hands. Ekenvall et al suggested that musculoskeletal load might give rise to neuropathy. This is not supported by our studies. There were no associations between symptoms of the neck, shoulders, or arms and a low SI, high 2PD, sensorineural symptoms, reduced strength, or manual performance. Symptoms, in the hands of mainly the dentists were associated with a low SI, sensorineural symptoms, high $2 \mathrm{PD}$, and reduced strength. No such associations were seen among the dental assistants or controls, although a relatively high percentage of the controls had symptoms of the hands. The dental assistants did not show any signs of neuropathy in the vibrograms for frequencies above $8 \mathrm{~Hz}$, and did not report an increased frequency of sensorineural symptoms. Detailed clinical examination of our groups, however, did not show different frequencies of musculoskeletal symptoms or diagnostic patterns in dental assistants and dentists (unpublished data). Hence, it is likely that the main part of the subjective and objective hand phenomena were caused by the exposure to vibration, and not by musculoskeletal load associated with work.

There were no associations between mercury concentrations in blood cells, blood plasma, or urine and the functional tests. Effects of mercury on the peripheral nervous system occur only at higher exposures. ${ }^{36}$ Further, the dental assistants had the highest concentrations of mercury, but showed little difference in the functional parameters.

The decrease of strength was rather severe, and the impairment in tactile sensitivity and performance, although not great, was still notable. They constitute a serious problem among dentists and dental hygienists as these professions require excellent hand functionprecision, sensibility, fine manipulation, and grip force. The dentists were more affected than the hygienists. This may be partly because the dentists had longer durations of exposure. Also, the dentists use mostly high speed and low speed hand pieces, whereas the dental hygienists handle ultrasonic scalers and low speed hand pieces to a greater extent. The problem is particularly serious, as the duration of exposure every day is limited. Dentists and hygienists use vibrating tools for only about 75 minutes a day. ${ }^{37}$ This is in accordance with recordings made of the present hygienists (unpublished data).

It is obvious that dental devices with lower exposure to vibration must be developed. A drawback is that too little is known about the conduction of energy from the instruments to the hand, and about how to reduce this. One simple measure, that can be applied to already existing devices, is to teach the personnel to use only minimum grip force, as this would reduce the transmitted energy. ${ }^{38}$ These studies were supported by grants from the Swedish
Work Environment Fund and the Medical Faculty, Lund
University. Support was also given by the County Council of
Blekinge and the County Council of Malmöhus. Valuable
assistance was given by Ms Ingrid Hallberg, Dr Carl-Gunnar
Lingström, Dr Kjell Mårtensson, Ms Vivi Svensson, Mr
Anders Ekholm, Ms Gudrun Persson, Dr Andrejs Schütz, and Ms Nancy Simonsson. 
1 National Institute for Occupational Safety and Health. Criteria for a recommended standard. Occupational exposure to hand-arm vibration. Cincinnati, OH: US Department of Health and Human Services. Public Health Service, Centers for Disease Control, Division of Standards Centers for Disease Control, Division of Standards Development and Technol

2 Pyykkö I. Clinical aspects of the hand-arm vibration syndrome. A review. Scand $f$ Work Environ Health 1986;12:439-47.

3 Lundström R. Hand-arm vibrationer. Kunskapsläget för bedömning av skaderisker. Hand-arm vibration. Current knowledge for risk evaluation. Uppsala: Ord and Form AB, 1989. (In Swedish)

4 Andersson R, Bergström B, Dandanell R, Engström K, Grave B, Magnusson $\mathrm{L}$, et al. Undersökning av vibrationsmiljön och skaderisker vid arbete med tandläkarborrar med hijga varvtal och ultraljudsverktyg. Study of the vibrationhöga varvtal och ultraljudsverktyg. Study of the vibrationexposure and the occupational risks in work with dental drills with high acceleration levels and ultrasonic devices. Linköping:

5 Lundström R, Lindmark A. Effects of local vibration on tactile perception in the hands of dentists. Fournal Of Low Frequency Noise and Vibration 1982;1:1-11.

6 Ekenvall L, Nilsson B, Falconer C. Sensory perception in the hands of dentists. Scand $\mathcal{f}$ Work Environ Health 1990;16:334-9.

7 Hjortsberg U, Rosén I, Ørbæk P, Lundborg G, Balogh I. Finger receptor dysfunction in dental technicians exposed to high-frequency vibration. Scand $f$ Work Exposed to high-frequency vibron Health 1989;15:339-44.

8 Shapiro I, Sumner A, Spitz L, Cornblath D, Uzzel B, Stiip $\mathrm{I}$, et al. Neurophysiological and neuropsychological function in mercury-exposed dentists. Lancet 1982; i: $1147-50$

9 MacDonald G, Robertson M, Erickson J. Carpal tunnel syndrome among California dental hygienists. Dental Hygiene 1988:322-8.

10 Wieslander G, Norbäck D, Göthe CJ, Juhlin L. Carpal tunnel syndrome (CTS) and exposure to vibration, repetitive wrist movements and heavy manual work: a case-referent study. $\mathrm{Br} \mathcal{F}$ Ind Med 1986;46:43-7.

11 Rundcrantz B-L, Johnsson B, Moritz U. Cervical pain and discomfort among dentists. Epidemiological, clinical, discomfort among dentists. Epidemiological, clinical

12 Åkesson I, Schütz A, Attewell R, Skerfving S, Glantz P-O. Mercury and selenium status in dental personnelimpact of amalgam work and fillings. Arch Environ Health 1991;46:102-9.

13 Albers JW, Cavender GD, Levine SD, Langolf GD. Asymptomatic sensorimotor polyneuropathy in workers exposed to elemental mercury. Neurology 1982;32: 1168-74.

14 Kuorinka I, Jonsson B, Kilbom $\AA$, Vinterberg H, BieringSørensen F, Andersson G, et al. Standardised Nordic questionnaires for the analysis of musculoskeletal sympquestionnaires for the analysis of

15 Lundborg G, Sollerman C, Strömberg T, Pyykkö I, Rosén B. A new principle for assessing vibrotactile sense in vibration-induced neuropathy. Scand $\mathcal{f}$ Work Environ Health 1987;13:375-9.

16 Lundborg G, Lie-Stenström AK, Sollerman C, Strömberg T, Pyykkö I. Digital vibrogram: a new diagnostic tool for sensory testing in compression neuropathy. $\mathcal{F}$ Hand Surg 1986;5:693-9.

17 Lundborg G, Dahlin LB, Lundström R, Necking LE, Strömberg $T$. Vibrotactile function of the hand in compression and vibration-induced neuropathy. Sensibility index-a new measure. Scand F Plast Reconstr Surg Hand index-a new measure.

18 Mober E Objective methods for determining the functional value of sensibility of the hand. $\mathcal{F}$ Bone foint Surg
Br 1958;40:454-76.

19 Moberg E. Criticism and study of methods for examining sensibility in the hand. Neurology 1962;12:8-19.

20 Sperling L, Jonsson B. Funktionstestning av arbets- och skyddshandskar. Test of hand function at work with protective gloves. In: Sperling L, Jonsson B, Holmer I, eds. tandfung Handfunktion och handskydd vid arbete med handskar. Solna: Arbetarskyddsverket. Arbete och Hälsa 1983;30: Solna: Arbetarskydds

21 Gehan EA. A generalized Wilcoxon test for comparing arbitrarily singly-censored samples. Biometrika 1965; 52:203-23.

22 Brammer AJ, Taylor W, Lundborg G. Sensorineural stages of the hand-arm vibration syndrome. Scand $f$ Work Environ Health 1987;13:279-83.

23 Gemne G, Pyykkö I, Taylor W, Pelmear PL. The Stockholm workshop scale for the classification of coldinduced Raynaud's phenomenon in the hand-arm vibration syndrome (revision of the Taylor-Pelmear scale). tion syndrome (revision of the Taylor-Pelm
Scand $\mathcal{F}$ Work Environ Health 1987;13:275-8.

24 Goff GD. Vibration perception in normal man and medical patients. $\mathcal{F}$ Neurol Neurosurg Psychiatry 1965;28: 503-9.

25 Verrillo $R$. Comparison of vibrotactile threshold and suprathreshold responses in men and women. Percept Psychophys 1979;26:20-4

26 Lundström R, Strömberg T, Lundborg G. Vibrotactile perception threshold measurements for diagnosis of sensory neuropathy. Int Arch Occup Environ Health 1992;64:201-7.

27 Lundström R. Effects of local vibration transmitted from ultrasonic devices on vibrotactile perception in the hands ultrasonic devices on vibrotactile perception in

28 Färkkilä M. Grip force in vibration disease. Scand $\mathcal{f}$ Work Environ Health 1978;4:159-66.

29 Färkkilä M, Aatola S, Starck J, Pyykkö, Korhonen O. Vibration-induced neuropathy among forestry workers. Acta Neurol Scand 1985;71:221-5.

30 Ho ST, Yu HS. Ultrastructural changes of the peripheral nerve induced by vibration: an experimental study. $\mathrm{Br} \mathcal{F}$ Ind Med 1989;46:157-64.

31 Lundborg G, Dahlin LB, Danielsen N, Kanje M. Vibration exposure and nerve fibre damage. $\mathcal{f}$ Hand Surg Am 1990;15:346-51.

32 Lundborg G, Dahlin LB, Danielsen N, Hansson HA Necking LE, Pyykkö I. Intraneural edema following exposure to vibration. Scand f Work Environ Health exposure to vil

33 Necking L-E, Dahlin LB, Fridén J, Lundborg G, Lundström R, Thornell LE. Vibration-induced muscle injury. An experimental model and preliminary findings. f Hand Surg Br 1992;17:270-4.

34 Takeuchi T, Takeya M, Imanishi H. Ultrastructural changes in peripheral nerves of the fingers of three vibration-exposed persons with Raynaud's phenomenon. Scand $f$ Work Environ Health 1988;14:31-5.

35 Gemne G, Lundström R, Hansson JE. Disorders induced by work with hand-held vibrating tools. A review of current knowledge for criteria documentation. Solna: rent knowledge for criteria documentation. Solna: Hälsa 1993;6:9-10.

36 Clarkson TW, Hursh JB, Sager PR, Syversen TLM. Mercury. In: Biological monitoring of toxic metals. New York; Plenum Press, 1988;199-246.

37 Andersson R. Exponeringstider vid användning av vibrerand utrustning inom tandvården. Exposure time in occupational exposure to hand-held vibrating tools in dentistry. Linköping: Landstinget i Östergötlands län. Landstingshälsan i Östergötland, 1986;7:1-4. (In Swedish)

38 Burström L, Lundström R. Mechanical energy absorption in human hand-arm exposed to sinusoidal vibration. Int Arch Occup Environ Health 1988;61:213-6. 